\title{
PERFORMANCE EVALUATION OF A TRADITIONAL WOODEN SHIP BY PRESERVED SKILL TECHNIQUES
}

\author{
YOSHIFUMI OHBUCHI ${ }^{1}$, HIDETOSHI SAKAMOTO ${ }^{2} \&$ MANABU SHIMIZU $^{1}$ \\ ${ }^{1}$ Graduate School of Advance Science Technology Research, Kumamoto University, Japan \\ ${ }^{2}$ Doshisha University, Japan
}

\begin{abstract}
Skills and techniques have been passed on for many years through the imitation of expert's skills by successors. Recently, the aging of experts and lack of successors has caused serious problems in changing social environments. It is worrying that superior traditional techniques and skills will disappear without succession in various fields. Therefore, it is required that those traditional techniques and skills specialized for everyone will be preserved and succeeded by changing into datum with objectivity and reproducibility. In this study, a handmade wooden ship constructed by a technician with a traditional skill is the research object, and a new preservation method using multimedia has been introduced. Multimedia used here consists of movies, pictures, sounds, documents and 3D-CAD datum. 3D-CAD is introduced as a media, and is applied to preserve and succeed the traditional skill. In the modelling of solid 3D-CAD, each part of the ship is made and assembled in same way with actual processes and dimensions, which is evaluated using modern analysis technology. On the other hand, one of the purposes of this study is quantitative evaluation of the ship constructed by traditional technician. FRP (Fiber Reinforced Plastics) ships mainly used today are designed based on the shapes of traditional wooden ships. Therefore, a new application of evaluated results of the ship will be realized in producing new ship shapes for tailored design. For these purposes, fluid-structure coupled CAE analysis is applied to the $3 \mathrm{D}$ wooden ship model. By means of fluid analysis, streamline of flowing around the ship body is evaluated. In addition, the pressure distribution caused by flow is obtained. Then, under the condition that the ship is floating on the sea, structural analyses can be performed by applying resultant pressure distribution. A smooth stress distribution was observed as a result, and a quantitative evaluation of handmade wooden ships by traditional technician succeeded. Also, the restoring force and stability of the ship can be calculated using the buoyancy and gravity. The new approach proposed here can be applied to tailored design of different shaped new ships.

Keywords: traditional skill, wooden ship, succession, preservation, performance evaluation, fluidstructure coupled analysis.
\end{abstract}

\section{INTRODUCTION}

Succession of the skills and techniques is very important in various fields. In Japan, a lot of special traditional skills which should be succeeded exist in many places. However, succession of the skills and techniques is becoming difficult in these days.

Skills and techniques have been succeeded for many years through imitating skill of master by successor. Although the relationship between the master and apprentice is necessary for succession of skills and techniques, however, aging of these masters and shortage of successors became serious problem. Therefore, it is required that the traditional skill specialized in an individual will be preserved and succeeded by transforming into data with objectivity and reproducibility [1]. We proposed the new preservation method by using datum based on multimedia. Here, multimedia means document, sketch, drawing, photograph, movie, voice, sound, and 3D-CAD datum; as a new medium. Fig. 1 shows the conceptual diagram of this study.

In this study, a handmade wooden ship constructed by a shipbuilder technician with traditional skill is the research object, and new preservation method using multimedia database with HTML format had been introduced [2]. 3D-CAD is introduced as a new media, 
and is applied to preserve and succeed the traditional skill, and a learning method using digital tools were developed [3], [4]. In those our previous work, the 3D-CAD ship model had been reproduced according to not only real shapes and dimensions but also the actual production processes. Each part of the ship had been made and assembled in similar way with actual processes and dimensions in 3D-CAD modelling.

In this study here, we try to evaluate old wooden ship made by traditional skill and technique by means of modern analysis technology using the model reconstructed on solid 3D-CAD. By using of CAE technology, quantitative evaluation of the model on stress analysis, fluid dynamic analysis, etc. will be enabled. The purpose of this study is quantitative evaluation of wooden ship constructed based on experience of a skilled technician. Finally, it aims to enable tailored design of new ship shape suitable for the purpose of fishing before actual shipbuilding as an application. Because this kind of ship is now made from FRP, but molded by the shape based on the traditional wooden ship which has been succeeded to from generation to generation.

\section{OBJECT OF STUDY}

A handmade Japanese wooden ship called Tsunoshima-denma ship is the object of study. Fig. 2 shows the Tsunoshima-denma ship, and its length is about $6 \mathrm{~m}$. This ship is mainly used for Sokomi-Ryo, with stopping the ship in shallows and captures the marine product in bottom of the sea such as the sea urchin, the top shell, ormers, and seaweeds. The ship is made by traditional skill and technique existed in Yamaguchi prefecture, the method of shipbuilding is becoming extinct. The wooden ship cannot be seen in these days because it is now made of FRP (Fiber Reinforced Plastic). The production of wooden ship greatly decreased because of the spread of FRP ship.

From 2002 to 2003, Tsunoshima-denma ship was reproduced by a shipbuilder in Hohokutown of Yamaguchi prefecture as a town event. In the shipbuilding, all processes were carefully observed and recorded by many staff for six months. The amount of recorded media is video tapes of 141 hours, 173 pages of notebooks including documents and sketches, great number of photographs. Then introducing digest video DVD [5] and 197 pages of report [6] were published by Hohoku-town. In this study, two reference materials described below were mainly used.

1. The videos which recorded all processes and operations during the constructing of the wooden ship by the expert.

2. The document text of actual work written by museum attendants (they are not expert about shipbuilding) during making of wooden ship.
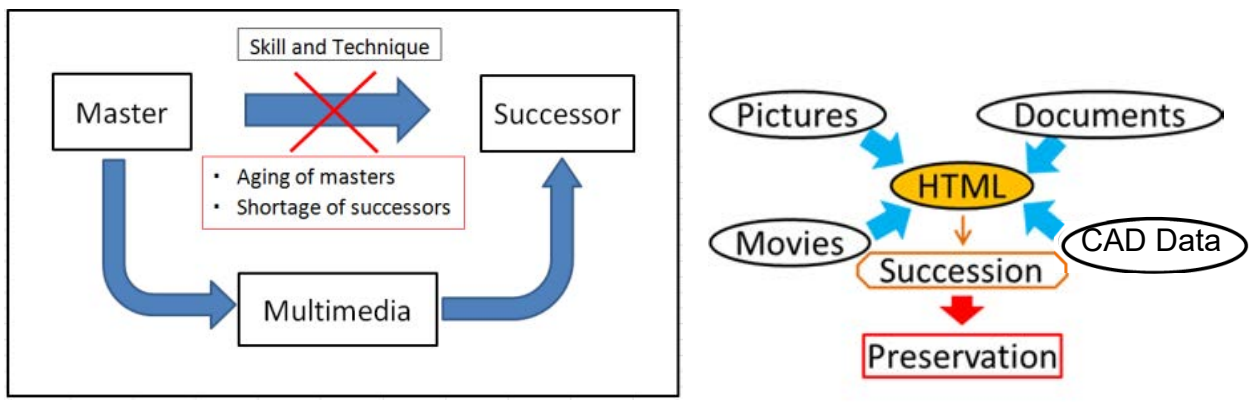

Figure 1: Conceptual diagram. 


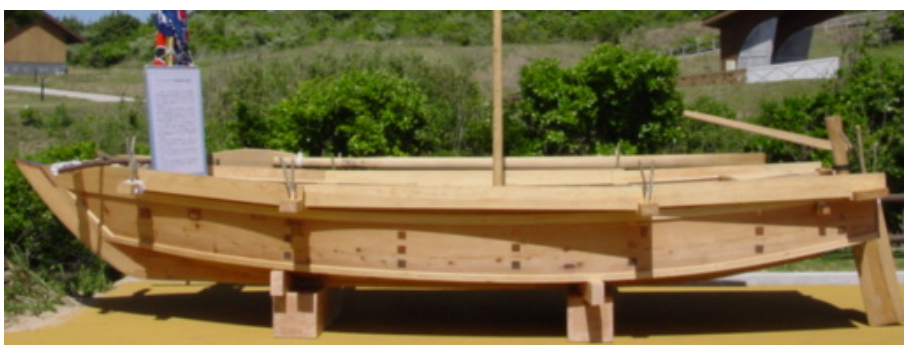

Figure 2: The Tsunoshima-Demma ship.

\section{REPRODUCTION OF 3D-CAD MODELS}

\subsection{Making of real structure CAD model}

A new evaluation of the tradition skill is tried by reproducing the target wooden ship. The models are reproduced on solid 3D-CAD from measured dimension of each part. All parts of the ship are made and assembled by 3D-CAD according to the procedure which is corresponding to the actual production process as shown in Fig. 3. This work is reproduction of the skill, and it becomes a modelling for CAE. That is, stress analysis, flow analysis, etc. by means of functions of CAE will become possible for quantitative evaluation of performance of the ship.

Fig. 4 shows an example of making according to actual fabrication procedure. It shows an enlarged view of stem connected to the bottom of ship. Fig. 4(a) shows already assembled parts. After assembling, the bottom part is processed to fit stem shape, as shown in Fig. 4(b) and 4(c).

By means of this proposed modelling method, the relationship property with other materials and the timing of the combination are preserved as a history of CAD. This is a powerful merit for preservation of skill and making process. All of work was performed according to actual processes. Finally, complete CAD model was made as shown in Fig. 5.

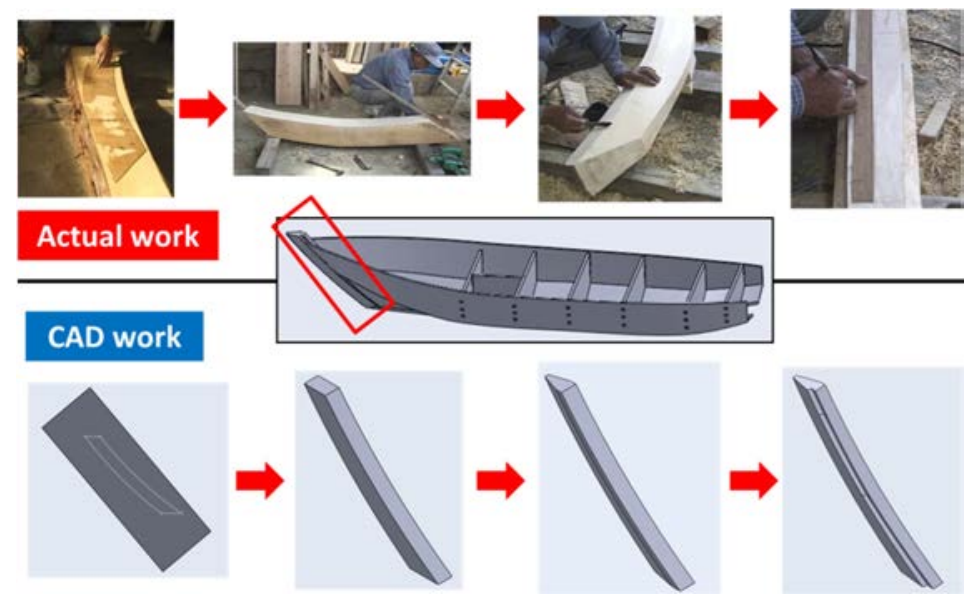

Figure 3: Corresponding actual work and CAD work. 

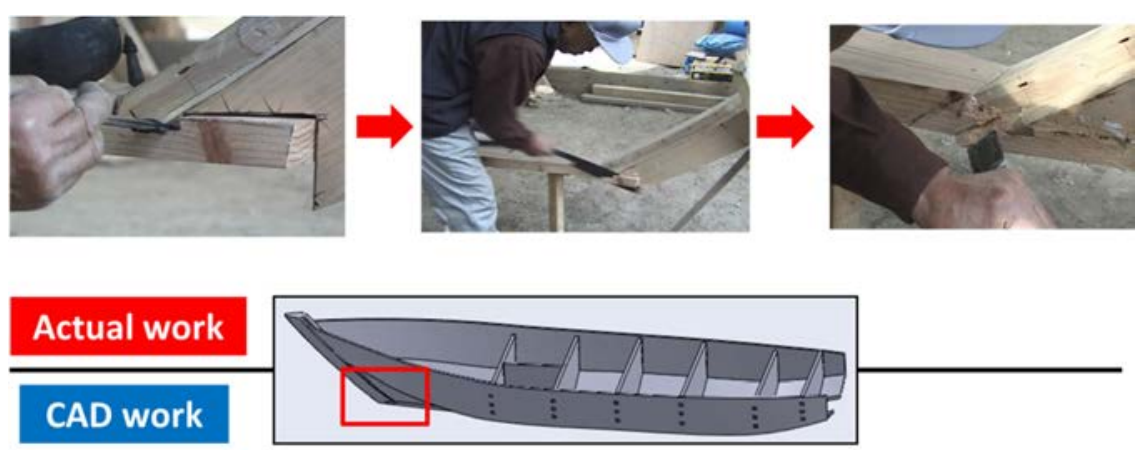

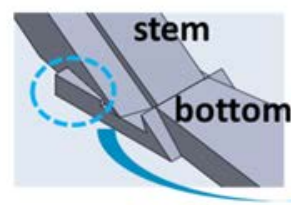

(a)

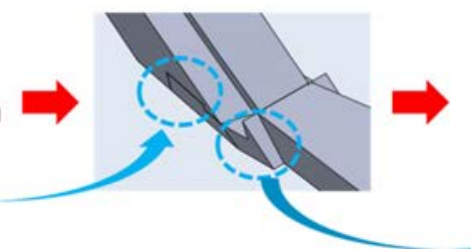

(b)

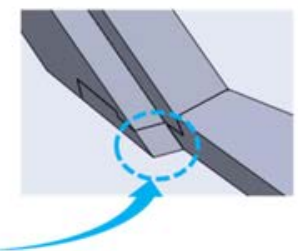

(c)

Figure 4: Modelling of fabrication procedure.
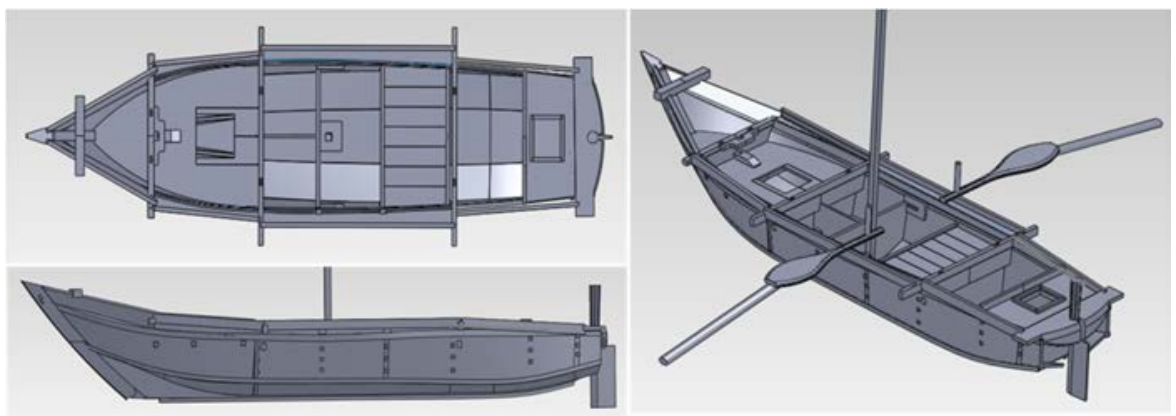

Figure 5: Complete CAD model.

\subsection{Modelling of different shape ship}

The model with different shape from the original ship is produced in order to examine the change in characteristics influenced by difference of ship shape. The modified models whose width is $12 \%$ narrower and wider than an original initial configuration. As shown in Fig. 6 of narrow model, the ship width is reduced $12 \%$ by means of changing the position of topside. The height of each component is fixed as it is, and changed only the position of width direction. Therefore, the positions of bottom edge of topside and the side edge of bottom are changed, and the angle of middle plate to a horizontal plane changes as shown in Fig. 6. In addition, each part of the model is modified corresponding to the part deformed. Thereby occurring of gap or interference between other parts can be avoided when each part is reshaped. The original shape and modified wide shape model are shown in Fig. 7. 


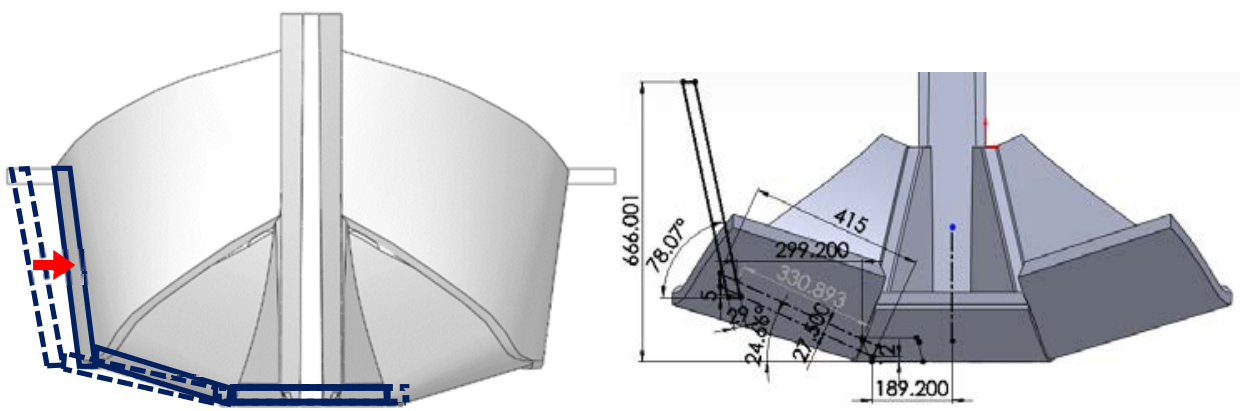

Figure 6: Modifying of ship shape; narrow shape model.

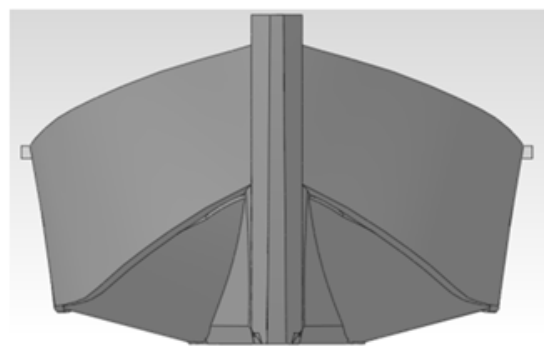

a. Original model

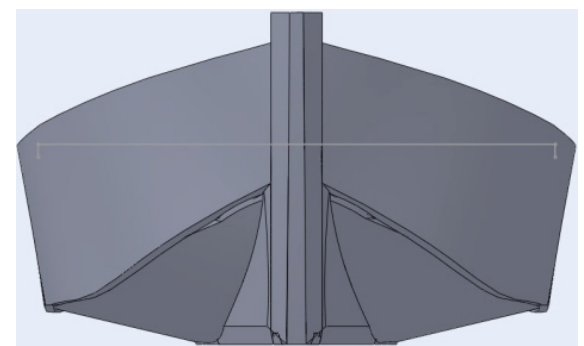

b. Modified wide shape model

Figure 7: Different ship shapes.

\section{STABILITY EVALUATION OF SHIP}

One of the important parameters which characterize the performance of the ship is stability. Because targeted Tsunoshima-Denma is a ship for Sokomi-Ryo with stopping the ship in shallows and capturing marine products, the higher stability is required. The stability is calculated from coordinates of canter of buoyancy and canter of gravity, and the displaced volume (volume in the part where the ship has been flooded) as shown in Fig. 8 using functions of CAD, and compared for three models described in the previous section.

The stability is shown in Fig. 9 as the righting couple for ship posture angle by using three different shape CAD models. The relation between the width of the ship and stability can be easily evaluated, because the coordinates of center of buoyancy and center of gravity of the ship in arbitrary posture can be easily calculated by using 3D-CAD model. Since the righting couple of these three ships were compared for the same buoyancy, it can be said that the stability is high when the righting couple caused at the same angle is large.

As the result, the wide model shows high stability and the narrow model shows low stability in comparison with original model. In addition, the gradient of tangent of righting couple curve at each plot in the graph of Fig. 9(a) is plotted in Fig. 9(b). Because targeted Tsunoshima-Denma is a ship for Sokomi-Ryo with stopping the ship in shallows and capturing marine products, the gradient of righting couple around 0 degrees is important. By means of technique introduced here with the 3D-CAD model, it become easy to design optimum shape for stability according to each purpose of ship. 

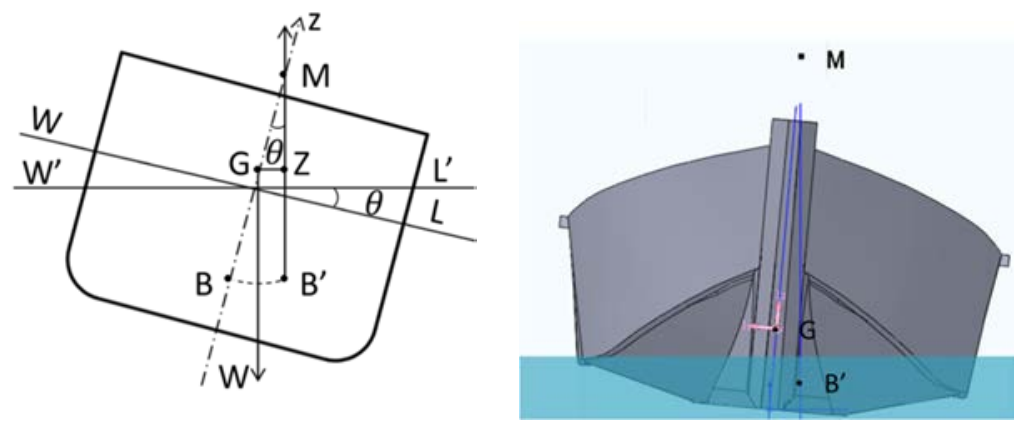

Figure 8: Stability evaluation of ship.
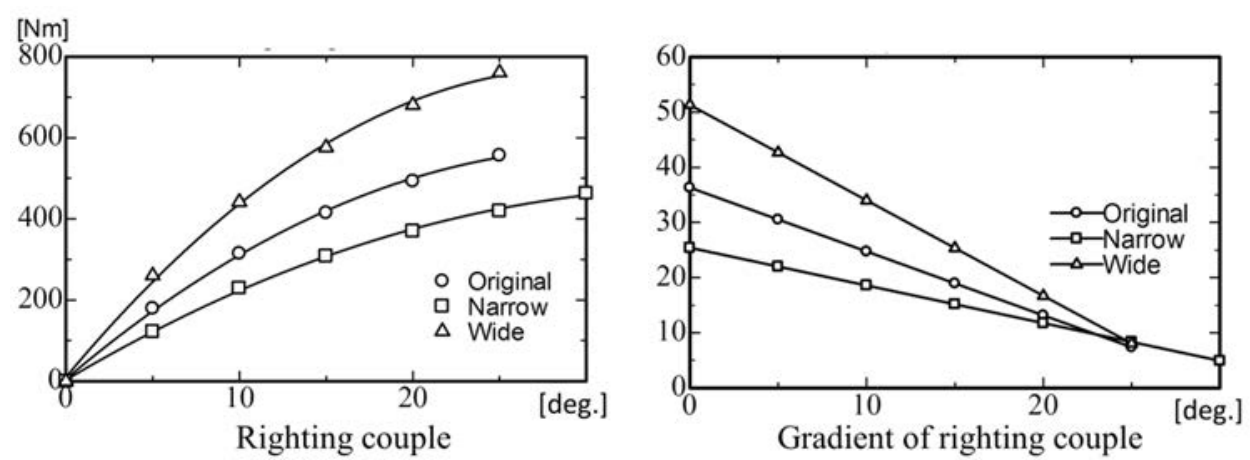

Figure 9: Righting couple and its gradient.

\section{FLUID-STRUCTURE COUPLED ANALYSIS}

At first, the fluid analysis is performed to three models of different shape with calculation volume where actual height of sea surface (draft) was assumed. Next, the fluid pressure on the ship surface, which is obtained from fluid analysis, is applied to the structure analysis. Then the coupled analysis can be performed as above procedure.

\subsection{Fluid Analysis}

Fluid analysis is performed to the three different shape models described above. Height of water surface is set to $170 \mathrm{~mm}$ from the bottom of ship, corresponding to the actual draft.

As analytical condition, water flow rate is $1 \mathrm{~m} / \mathrm{s}$ from forward and air is stationary. Accurate buoyancy is obtained in structure analysis by setting the two kinds of fluids (water and air) [7].

\subsection{Structure analysis}

Surfaces of each component are bonded as continuum solid in assembling process of modelling. However, all interfaces should not be joined. Some kind of adjusting is necessary not to generate the stress concentration [8]. For example, when a force of constraint becomes too much than the joining force by low elasticity of adhesive, when considering peeling off 
of adhesive, etc. Sometimes, decreasing the number of bonding surfaces is applied, according to the situation. For instance, surfaces of sharp part, as shown in Fig. 10(a) and (b), are not bonded to avoid occurrence of discontinuous stress distribution. The surfaces S1-S5 in Fig. 10(b) are interfaces with other parts, but S2 is not bonded in the modelling. In the case that all interfaces are bonded, stress concentration will occur due to high restraint as shown in Fig. 10(c). Such high resistance compared with actual bonding will cause slipping or peeling off when using elastic glue. By applying these treatments, stress concentration and discontinuous distribution is avoided as shown in Fig. 10(d).

The model is fixed by several points as boundary condition for structure analysis as shown in Fig. 11 [8]. The point P1 on the bottom near the center of buoyancy and center of gravity is fixed in three axial directions of orthogonal coordinate system. Other points P2, P3 and P4 are fixed in $\mathrm{X}, \mathrm{Y}$ and $\mathrm{Z}$ direction respectively. The gravity of ship and crews in each shape model balances its buoyancy. The gravity of crew is applied by loading at seating surface (shaded areas in Fig. 11). Then the fluid-structure coupled analysis will be applied to the model by combining the processes described above.

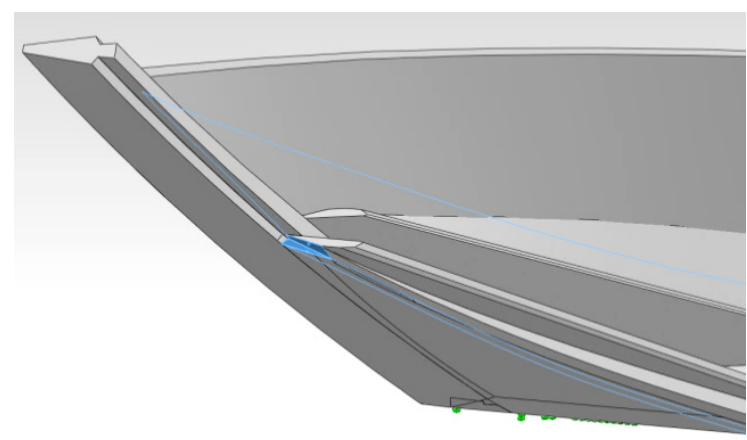

(a)

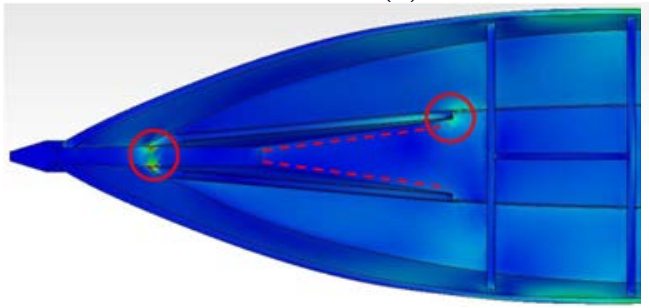

(c)

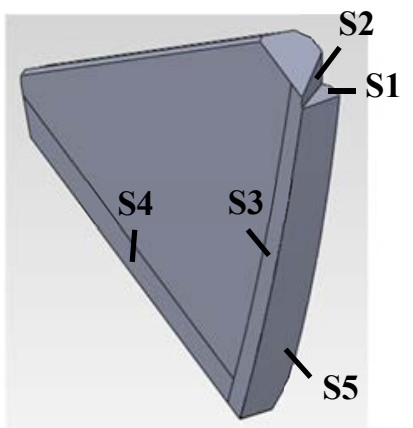

(b)

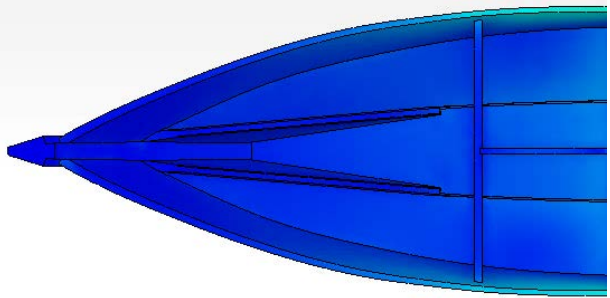

(d)

Figure 10: Adjusting interface condition for avoidance of stress concentration.

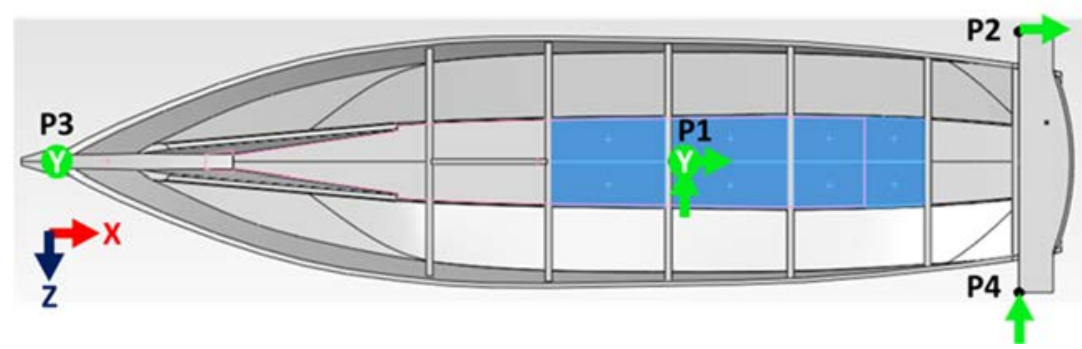

Figure 11: Fixed conditions and seated areas. 


\section{RESULTS AND DISCUSSIONS}

\subsection{Fluid analysis}

Streamline around the ship and dynamic pressure distribution caused by flow are evaluated by fluid analysis (Fig. 12). By applying fluid analysis, streamline and dynamic pressure distribution can be obtained. The analysis results of three models of different shape are shown in Table 1. The higher the draft (water line from the bottom), the larger the influence of the ship shape and the difference in Cd value also become large. However, when the draft is low as same as actual level, $\mathrm{Cd}$ value shows almost same value for changes of ship width. Therefore, it can be evaluated that the shape of targeted ship has both high stability and high sailing performance, considering this result and above-mentioned stability. From this result, the original ship made based on the experiences of skilled traditional shipbuilder is a kind of optimum shape in comparison with modified narrow and wide ships.

\subsection{Verification of flow analysis using simplified model}

The fluid analysis was performed to evaluate the forces act on the ship body by fluid flow, and it will be applied to structure analysis to obtain structural property, i.e. stress distribution, deformation, etc. Here, the fluid analysis result should be verified whether it has validity with actual tow test result. However, a tow test needs large pool and a lot of time. Therefore, the experimental result data of other researcher in faculty of fishers in Nagasaki University [9] is used for this verification.

The three ship shapes labelled M5, M18 and M19 among 22 ships in the reference research were selected for verification of the fluid analysis. The method of the simplified modelling is described below. At first, the outlines of 13 cross sections in hull diagram are sketched in
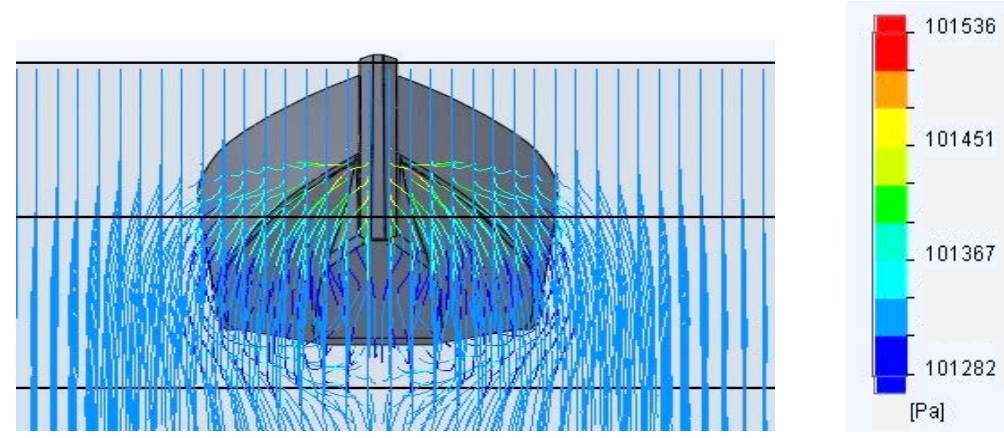

Figure 12: Streamline and dynamic pressure.

Table 1: Buoyancy and drag.

\begin{tabular}{|c|c|c|c|c|c|c|c|}
\hline Draft & Shape & \multicolumn{2}{|c|}{ Drag [N] } & \multicolumn{2}{c|}{ Buoyancy [N] } & \multicolumn{2}{c|}{ Cd } \\
\hline \multirow{2}{*}{$\begin{array}{c}170 \\
{[\mathrm{~mm}]}\end{array}$} & Original & 26.3 & -- & 6779 & -- & 0.279 & -- \\
\cline { 2 - 8 } & Narrow & 22.8 & $-13.0 \%$ & 5915 & $-12.7 \%$ & 0.279 & $0.0 \%$ \\
\cline { 2 - 8 } & Wide & 29.2 & $11.1 \%$ & 7447 & $9.9 \%$ & 0.281 & $0.6 \%$ \\
\hline \multirow{2}{*}{$\begin{array}{c}510 \\
{[\mathrm{~mm}]}\end{array}$} & Original & 76.7 & -- & 28345 & -- & 0.225 & -- \\
\cline { 2 - 8 } & Narrow & 63.7 & $-16.9 \%$ & 25003 & $-11.8 \%$ & 0.213 & $-5.6 \%$ \\
\cline { 2 - 8 } & Wide & 88.0 & $14.7 \%$ & 31557 & $11.3 \%$ & 0.231 & $2.5 \%$ \\
\hline
\end{tabular}


CAD. Next, the outline reference point is connected with three-dimension spline as a guideline. Finally, the lofted surface of ship body is extruded. The hull diagram used for the modelling and the side vies of completed three models are shown in Fig. 13.

The coefficient of resistance by experimental and analytical tow test for three models above mentioned are shown in Table 2 . The error margin for these three models is within 5 percent. Since the analytical value close to experimental measurements was obtained, the fluid analysis performed here has enough validity. Therefore, it is able to use as the load of the hydrodynamic force to the structure actually by applying the result to structure analysis.

\subsection{Structure analysis}

Next, the structural condition of ship floating on the sea is simulated applying calculated pressure distribution to structure analysis. The result obtained from the flow analysis is applied to the structure analysis. As the result of a fluid-structure coupled analysis, Fig. 14 shows the equivalent stress distribution of three models described above, in condition of

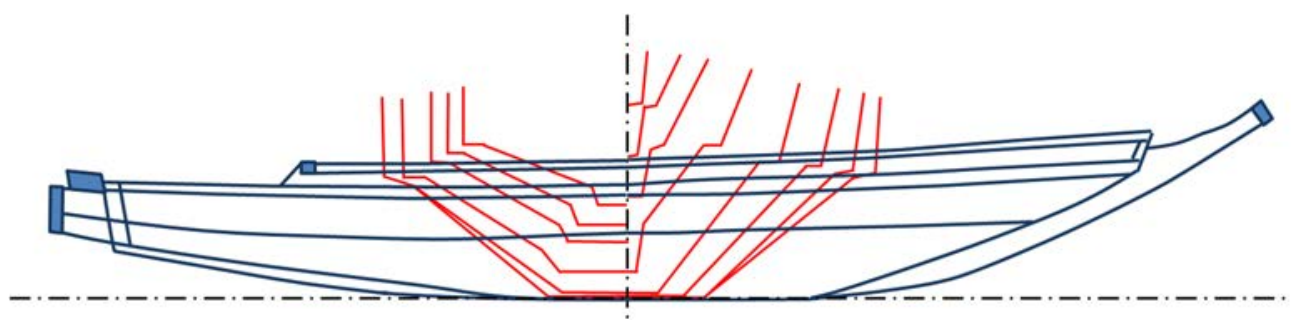

(a) Hull diagram of label M5 ship

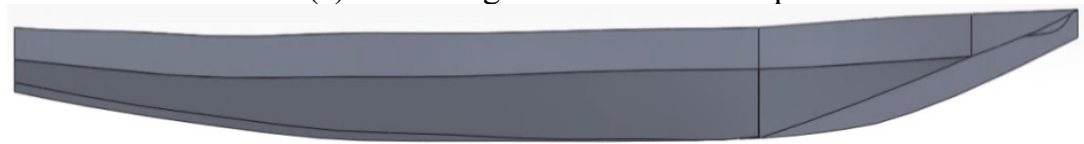

(b) Model of label M5 ship

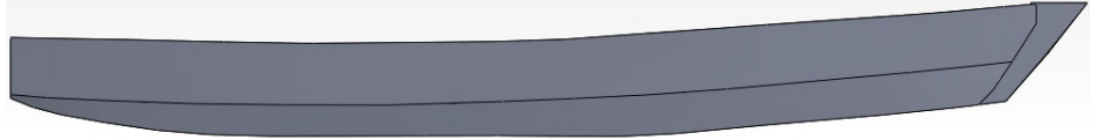

(c) Model of label M18 ship

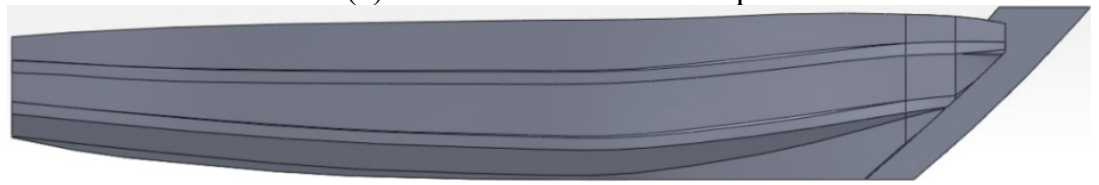

(d) Model of label M19 ship

Figure 13: Hull diagram and simplified models for verification.

Table 2: Coefficient of resistance.

\begin{tabular}{|c|c|c|c|}
\hline Label & Experiment & Analysis & Error \\
\hline M5 & 0.0315 & 0.0312 & $0.3 \%$ \\
\hline M18 & 0.0220 & 0.0231 & $-5.0 \%$ \\
\hline M19 & 0.0514 & 0.0492 & $4.3 \%$ \\
\hline
\end{tabular}




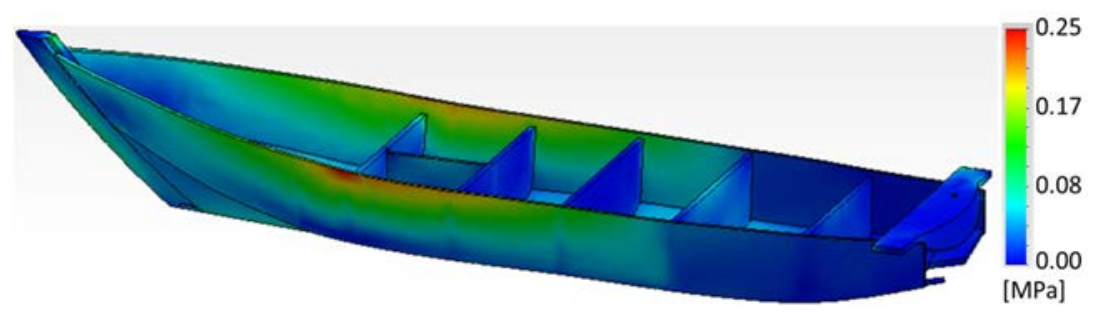

(a) Original model

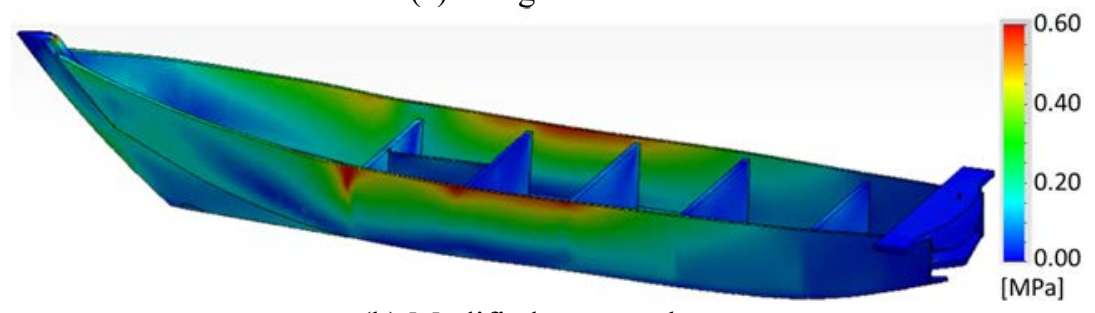

(b) Modified narrow shape

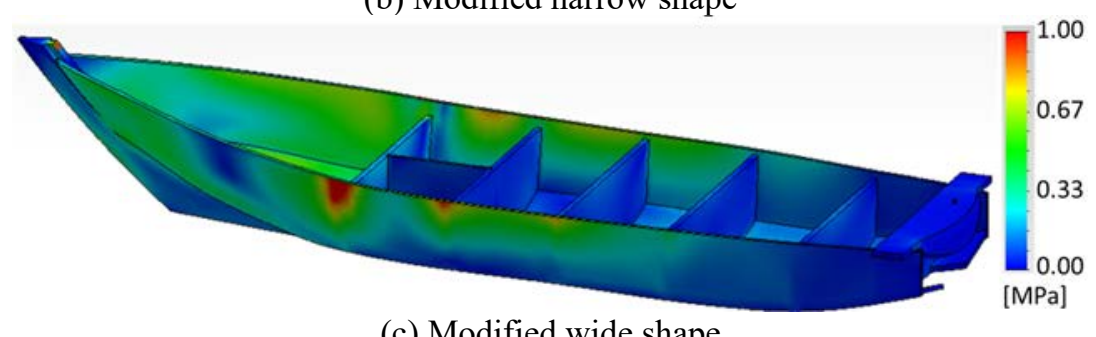

(c) Modified wide shape

Figure 14: Comparison of stress distribution due to shape.

$170 \mathrm{~mm}$ draft and $1 \mathrm{~m} / \mathrm{s}$ flow velocity. The draft was adjusted to the same value in the analysis. It was guessed that the maximum stress occurs in the wide model because strong buoyancy act to the ship body for same draft value. However, the maximum value in the narrow model is $0.6 \mathrm{MPa}$ though the maximum value in the original model is $0.25 \mathrm{MPa}$. As for the original model, the stress is lower than the narrow model though strong force has been applied from the outside. It is guessed that it is caused by partially biased stress.

The narrow model with 0.6 MPa and wide model with 1.0 MPa of maximum stress show the maximum stress concentration at the vicinity of separation board at forward part of ship. The gentlest stress distribution is shown in the original model. Since the variation of stress distribution in the original ship is a little compared with other shape models, it is confirmed that the force acting to the ship body is well distributed to whole of the ship. Therefore, it is understood that the shape decided based on the experience of traditional technician is a kind of optimum design. Consequently, quantitative evaluation of ship constructed by traditional technician is enabled by using CAE method. It will help for tailored design in production of new ship shapes.

\section{CONCLUSIONS}

In this study, we tried to evaluate old wooden ship made by traditional skill and technique by means of modern analysis technology using the model reconstructed on solid 3D-CAD. The 
purpose of this study was quantitative evaluation of wooden ship constructed based on experience of a skilled technician. The results obtained are summarized as follows.

1. The reproduction of making process will be available by using suitable corresponding CAD command, and the visualization of the making process will be possible by recording of the reproduction process using history function of CAD.

2. Quantitative evaluation of stability and sailing performance become possible by using righting couple calculated from CAD model and forces obtained by fluid analysis. From the evaluation, it is understood the shape of traditional wooden ship which was decided based on experience has both high stability and high sailing performance.

3. Since the variation of stress distribution of the original ship is a little compared with other shape models, it is confirmed that the force acting to the ship body is well distributed to whole of the ship. Therefore, it is understood that the shape decided based on the experience of traditional technician is a kind of optimum design.

4. The evaluation of the performance and strength of the ship becomes possible by using $\mathrm{CAD}$ and $\mathrm{CAE}$ analysis before production. It will help for tailored design in production of new ship shapes. When a new ship is produced, the optimum design corresponding to the usage and the purpose becomes possible.

\section{ACKNOWLEDGEMENTS}

We would like to show our greatest appreciation to Mr. Masahiro Hatsuno, the master of shipwright, who reconstructed the wooden ship and he also gave us many useful advices. Mr. Toru Yoshidome is a curator in the Shimonoseki city Hohoku Museum and gave us a lot of research materials. This work was supported by JSPS KAKENHI Grant Number 22500929.

\section{REFERENCES}

[1] Hiyama, A., Doyama, Y., Miyashita, M., Ebuchi, E., Seki, M. \& Hirose, M., Wearable Display System for Handing Down Intangible Cultural Heritage. Virtual and Mixed Reality, Part II, HCII 2011, LNCS 6774, pp. 158-166, 2011.

[2] Shimizu, M., Ohbuchi, Y. \& Sakamoto, H., Preservation and Succession of Traditional Skill using Multimedia Technology. Proceedings of the 2nd International Joint Symposium on Engineering Education, pp. 37-38, 2012.

[3] Shirakawa, T., Ohbuchi, Y. \& Sakamoto, H., Development Wooden Ship Building Process Learning Method by Using Digital Engineering. Proceedings of the 3rd International Joint Symposium on Engineering Education, pp. 193-194, 2013.

[4] Shirakawa, T., Ohbuchi, Y. \& Sakamoto, H., Development of Traditional Skill and Technology Learning Method Using Digital Tools. Proceedings of the International Conference of Engineering Education and Research, 2, 2014.

[5] Hohoku town of Yamaguchi prefecture, Hometown Cultural Revival Project (digest version), Yamaguchi Prefecture Hohoku Hometown Rediscovery DVD, Bunka-Eiken Ltd., 2003 (in Japanese).

[6] Hohoku Shimonoseki municipal history folk customs material pavilion. TsunoshimaDenma Shipbuilding Report -Problem of Folk Customs Technology Succession, 2007 (in Japanese).

[7] Shimizu, M., Ohbuchi, Y. \& Sakamoto, H., Quantitative Performance Evaluation for Traditional Skill using CAE method. Proceedings of the 3rd International Joint Symposium on Engineering Education, pp. 169-170, 2013.

[8] Shimizu, M., Ohbuchi, Y. \& Sakamoto, H., Quantitative Performance Evaluation for Traditional Wooden Ship using CAE method. Proceedings of the Asian Conference on Engineering Education, pp. 131-135, 2014. 
94 Computational Methods and Experimental Measurements XVIII

[9] Takayama. H., Study of the Japanese Style of Small Fishing Boat, "Wasen" of its Hull Type and Kinematic Performance Concerned Running Resistance and Stability. Bulletin of the Faculty of Fishers, Nagasaki Univ., 82, pp.1-84, 2001 (in Japanese). 